\title{
The Synthesis of Ascorbic Acid in the Rat Deprived of Vitamin A with and without Addition of Chloretone
}

\author{
By L. W. MAPSON AND SONIA E. WALKER \\ Dunn Nutritional Laboratory, University of Cambridge and Medical Research Council
}

(Received 14 Fuly 1947)

There is as yet little evidence that any direct metabolic relationship exists in the organism between the water-soluble and fat-soluble vitamins. In the last ro years, however, a growing interest has developed in the possibility of an interdependence between vitamins $A$ and $C$. Work on this subject has been limited, and the results of previous experiments are confusing and inconclusive. The problem investigated has been mainly that of the effect of vitamin A deficiency on the ascorbic acid content of the blood and other body tissues. Rats and cattle appear to have been the chief animals used in these investigations.

Sure, Theis \& Harrelson (1939) found that single or repeated depletion of vitamin A caused a fall in the concentration of ascorbic acid in the tissues of rats. The main organs affected were the kidney, heart, liver and thymus gland. In order to eliminate any possible effect of inanition resulting from the vitamin A deficiency, these workers made preliminary experiments from which they concluded that fasting up to a period of I I days produced no change in the ascorbic acid content of the rat's tissues. Extending this work, they subsequently studied the effect of deficiencies of vitamins $B_{1}$ and $B_{6}$ and riboflavin, and found that an even greater loss of ascorbic acid from the tissues occurred in riboflavin deficiency. Sutton, Kaeser \& Hansard (1942) fed young rats with graded doses of vitamin $A$ for a period of 2 months and found that the level of ascorbic acid in the plasma ran parallel with the vitamin $A$ intake. They state also that the urinary excretion of ascorbic acid in rats on a vitamin A-free diet was lower than that of control animals receiving adequate amounts of the vitamin. Apparently no attempt was made to control the food intake of any of the rats. This occurrence of diminished urinary excretion of ascorbic acid in vitamin A-deficient rats was confirmed by Boyer, Phillips, Pounden, Jensen, Rupel \& Nesbit (r 942 ), who found that the fall was more marked in female than in male animals. These workers suggest that absence of vitamin A decreases the concentration of ascorbic acid in the tissues by interfering with its synthesis and not by causing excessive loss from the kidneys. Once again there was no control of food intake. Jonsson, Obel \& Sjöberg (1942, 1945) claim that a deficiency of vitamin $A$ in rats produced scurvy-like alterations in the teeth, in addition to a fall in the blood content of ascorbic acid. These dental changes were not affected by giving vitamin $\mathrm{C}$, but after the administration of vitamin $\mathrm{A}$ the condition improved and the blood values for ascorbic acid rose. The fact that deficiency of vitamin $A$ leads to marked degenerative changes in the dentine and enamel of teeth has, however, been recognized for many years (Wolbach \& Howe, 1933; Boyle, 1933; Mellanby \& King, 
1934; Orten, Burn \& Smith, 1937; Mellanby, 1939). Thus, although similar in some respects to the changes found in scurvy, the tooth abnormalities seen in vitamin $\mathrm{A}$ deficiency need not necessarily be due to, or be evidence of, a lack of ascorbic acid.

Phillips, Lundquist \& Boyer (1941) reported that the low level of ascorbic acid found in the plasma of young calves suffering from 'white scour' could be raised by feeding the animals with vitamin $A$ in the form of shark-liver oil. Boyer et al. (1942) found a lowered level of ascorbic acid in the blood and cerebrospinal fluid of calves which were severely deficient in vitamin $\mathrm{A}$, and this finding was confirmed by Moore (1946). In horses, however, it was shown that experimental vitamin A deficiency carried to a fatal termination had no effect on the concentration of ascorbic acid in the serum (Hart, Goss \& Guilbert, 1943). Rubin \& Bird (1943), working on chickens, also failed to confirm the relationship between vitamin $A$ intake and the ascorbic acid content of the body tissues.

The object of the present experiments was to re-examine the suggestion that a specific relationship exists between vitamin $\mathrm{A}$ and ascorbic acid. The experiments took the form of determining the level of ascorbic acid in the tissues of normal rats, of rats deprived of vitamin $A$, and of normal rats when food intake was restricted to be equal to that of rats deprived of vitamin $A$. The effect also was studied of administering chloretone to see whether the increased synthesis of ascorbic acid, which it is known to induce, occurred also in rats deprived of vitamin $\mathrm{A}$.

\section{Biological}

METHODS

Piebald and albino rats, of both sexes and of varying ages, were given a basal vitamin A-free diet containing: casein (A/E casein of Glaxo Laboratories Ltd.) 20, sucrose 60 , arachis oil $\mathrm{I} 5$ and salt mixture $5 \%$, with an additional $10 \%$ of dried yeast. Each animal received weekly supplements of vitamins $D$ and $E$, the former as one drop of Radiostol (British Drug Houses Ltd.) ( $\equiv 60$ i.u.), and the latter as I mg. $D L-\alpha$-tocopheryl acetate. Vitamin $A$ was supplied as one drop of halibut-liver oil ( $\equiv 1500 \mathrm{i}$.u.)/rat/week. Chloretone was dissolved in arachis oil, and five drops of this solution containing 10 or $20 \mathrm{mg}$. of the drug were given to each rat by a dropping pipette.

At the termination of each experiment the rats were killed with coal gas and blood was collected after their throats were cut. The livers and suprarenal glands were removed rapidly and their contents analysed for vitamins $\mathrm{A}$ and $\mathrm{C}$.

\section{Chemical}

Estimation of vitamin $A$. The livers were placed in $5 \%(\mathrm{w} / \mathrm{v}) \mathrm{KOH}$ solution and their vitamin $A$ content was estimated by the antimony trichloride method applied after the digestion of the tissues by alkali (Davies, 1933). When sufficient blood was available its vitamin A content was measured by a modification of Yudkin's (194I) method with a microphotoelectric colorimeter.

Estimation of ascorbic acid. Blood was collected directly into $6 \%(\mathrm{w} / \mathrm{v})$ trichloroacetic acid, and ascorbic acid was estimated by the method of Roe \& Kuether (1943). 
Ascorbic acid in the liver and suprarenal glands was measured after extraction with metaphosphoric acid by titration against 2:6-dichlorophenolindophenol (Harris \& Olliver, 1942).

For determining the urinary excretion of ascorbic acid, $24 \mathrm{hr}$. samples of urine were collected into dark bottles containing $10 \mathrm{ml}$. of $20 \%(\mathrm{w} / \mathrm{v}) \mathrm{HPO}_{3}$, and the ascorbic acid was measured by the same method as that used for blood. In the first experiment the metabolism cages used were made entirely of glass to avoid contamination of the urine with metallic impurities. In later experiments metal cages were used in which all the metal parts coming into contact with urine were cellulosed or waxed.

\section{RFSULTS}

\section{Effect of vitamin $A$ deficiency on the ascorbic acid content of the tissues and blood in rats receiving an unrestricted diet}

Albino male rats fed on the diet deficient in vitamin A were divided into two groups. Group I received no vitamin A and group 2 was given weekly one drop of halibutliver oil ( $\equiv I_{500} \mathrm{i} . \mathrm{u}$. .). Two to 3 weeks after growth had stopped some of the vitamin A-deficient rats were killed and their tissues were analysed for ascorbic acid, the rats receiving vitamin $\mathrm{A}$ being killed at the same time. The remaining vitamin Adeficient rats were maintained on the diet for a further period of 3 months and their diet was supplemented with 1500 i.u. vitamin A/rat/week (group 3). The results are shown in Table I, Exp. I.

The ascorbic acid content of the livers of the vitamin A-deficient rats was reduced, both in concentration and total amount, when compared with that found in the livers of the animals given vitamin $A$; the fall in concentration was less marked than the fall in the total amount. The ascorbic acid level in the blood showed a marked and significant difference between the two groups, the mean value for the deprived animals being only half that for the controls.

In the animals of group 3, given vitamin A after a period of deprivation, the ascorbic acid concentration in the liver and blood was found to be higher even than that of group 2, given vitamin A from the start, but in the suprarenal glands there was no such change. Although these findings might at first sight be interpreted as indicating that the vitamin A, administered after a period of deficiency, had stimulated the synthesis of ascorbic acid, it must be noted that these animals had grown considerably during the 3 months for which they had received vitamin $A$, and were, therefore, no longer comparable in size with those in groups $I$ and 2.

In a further experiment in which piebald rats were used instead of albinos, the ascorbic acid content of the tissues (blood and liver) was similarly reduced in the males as a result of vitamin A deficiency (see Table I, Exp. 3, groups I and 3). The decrease in the ascorbic acid in the blood of the vitamin A-deficient male animals was, however, less pronounced than with albinos. The difference $(0.29)$ between the means of the values for the ascorbic acid content of the blood of all the vitamin A-deficient and nondeficient, piebald male rats used in this work was found to be significant $(t$ found $=2.977$, $t$ tabulated for $P 0.05=2 \cdot 13$, for $P$ O.01 $=2 \cdot 95$ ). 


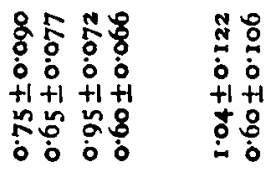

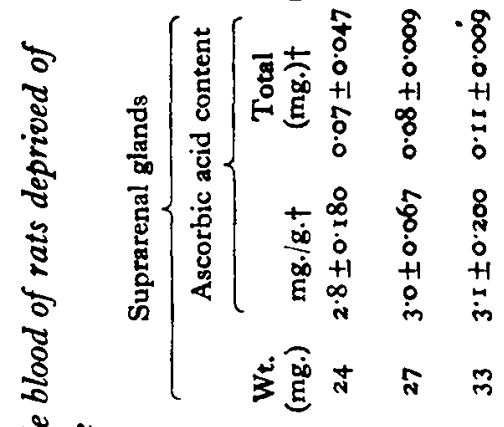

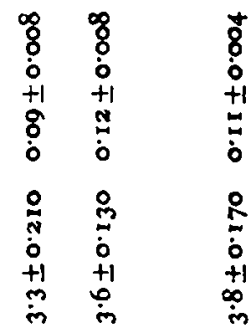

ष्ष

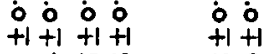

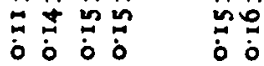

웅8 8 웅 8 응

4
$+1+1$
0

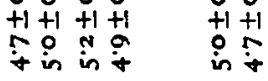

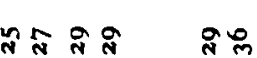

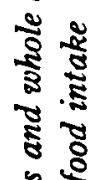

ช

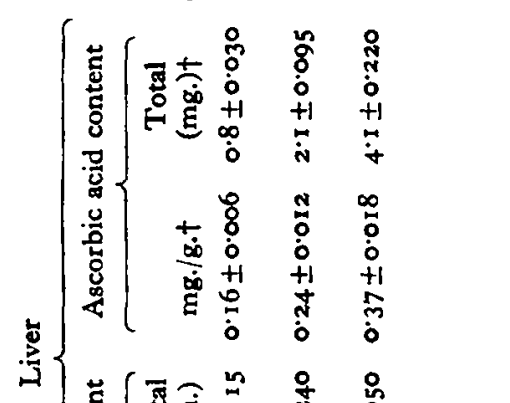

i $m$

i

$\begin{array}{lll}\infty & 0 & \\ 0 & 0 & 0 \\ 0 & 0 & 0 \\ 0 & 0 & 0 \\ +1 & +1 & +1 \\ & 0 & 0\end{array}$

웅의웅용

के

ind

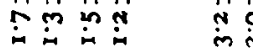

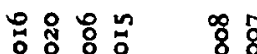

$\begin{array}{lll}0 & 0 & 0 \\ 0 & 8 & 0 \\ 0 & 0 & 0\end{array}$

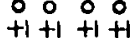

aro

$+1+1$

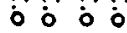

索管

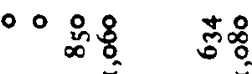

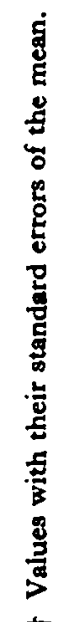

จุ๊

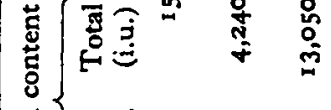

-

ֻั

○० ผัल

₹

趈

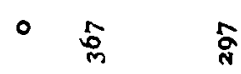

क.

₹

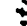

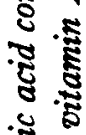

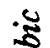

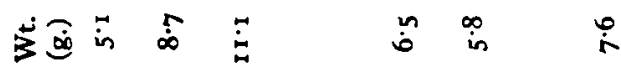

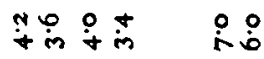

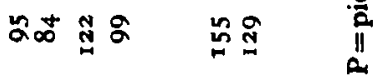

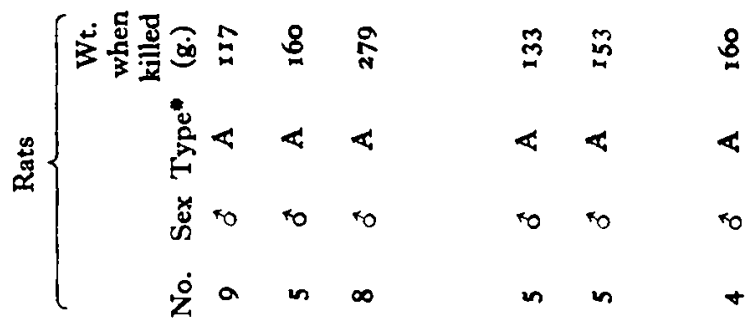

On or or on

toot root root

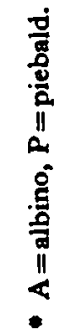

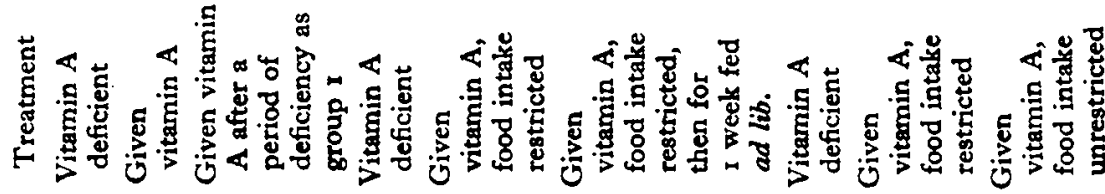

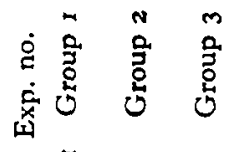

蒿

望

苍

을 
In contrast to these findings with the male animal, no decrease in the concentration of ascorbic acid was observed in the tissues of piebald female rats (Table 1, Exp. 3, groups I and 3). It is of interest to note that the concentration of ascorbic acid found in the blood and liver of piebald female rats was lower than that of corresponding male animals and, moreover, vitamin A deficiency in the male reduced the ascorbic acid content of blood and liver to approximately the same value as that found in the normal female.

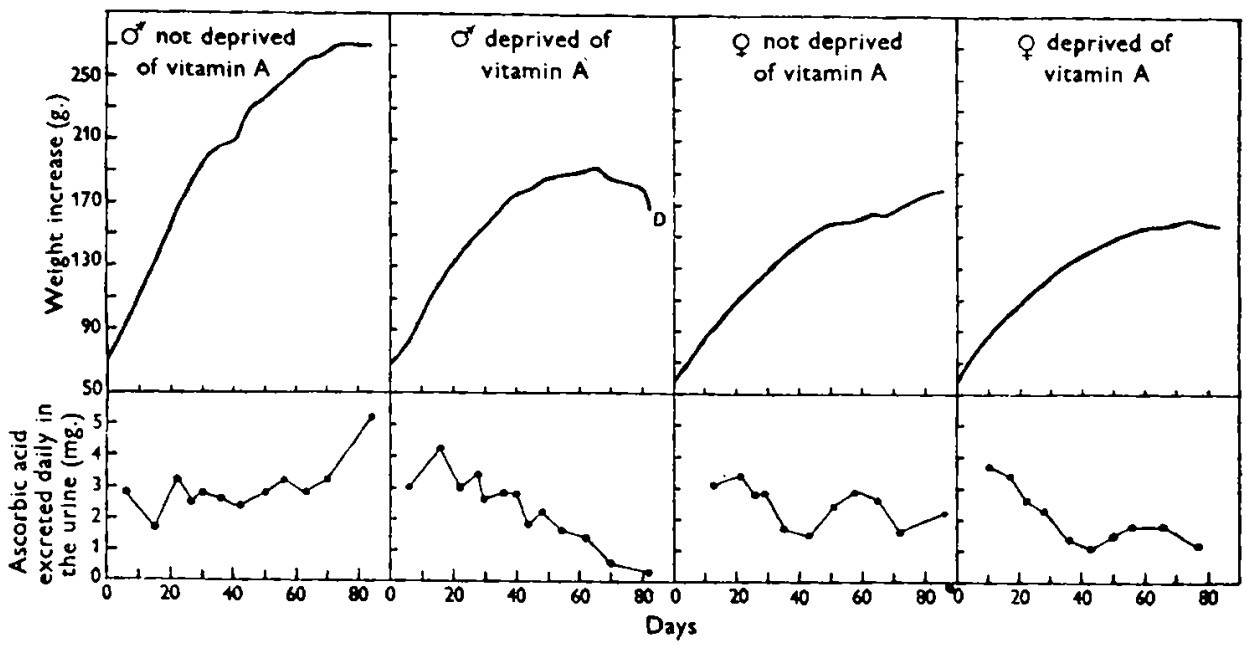

Fig. 1. Weight increase and amount of ascorbic acid excreted in the urine of representative male and female piebald rats deprived and not deprived of vitamin $A$.

These findings with the male animals may be interpreted as being due to: ( 1 ) an impairment of ascorbic acid synthesis in the organism; or (2) an excessive loss of ascorbic acid from the body due, e.g. to increased oxidation or renal excretion; or (3) other factors such as inequality of food intake between the normal and vitamin Adeficient animals. The validity of the first hypothesis can be established only after the second and third have been excluded.

\section{Effect of vitamin $A$ deficiency on urinary excretion of ascorbic acid in rats receiving unrestricted diets}

Piebald rats, $60-70 \mathrm{~g}$. in weight, were divided into two groups, both of which were maintained on the vitamin A-deficient diet. Group I received no vitamin A, while the second group was given 1500 i.u. vitamin $\mathrm{A} / \mathrm{rat} /$ week. The animals were kept in metabolism cages and $24 \mathrm{hr}$. samples of urine were collected from each rat twice a week and analysed for ascorbic acid. The procedure was continued for 80 days, by which time the deprived animals had either succumbed to the deficiency or begun to lose weight.

There was no evidence of any increased excretion of ascorbic acid in the vitamin Adeficient rats, in fact there was a tendency for a progressive fall as the deficiency developed. Typical results for rats of both sexes are shown in Fig. I. This fall in excretion was not observed in the animals receiving vitamin $A$, which generally were excreting more ascorbic acid at the end of the experiment than at the start. 
These results were subsequently confirmed in a later experiment when chloretone was used (see Fig. 2), in which the ascorbic acid excretion of the vitamin A-deficient rats, before the treatment with chloretone was applied, was below that of the nondeprived animals. In this last experiment the average daily excretion of ascorbic acid before treatment with chloretone was in the vitamin A-deficient animals I.I mg. and in the non-deficient group $5.7 \mathrm{mg}$.

It can be concluded, therefore, that the smaller amounts of ascorbic acid previously found in the tissues of vitamin A-deficient rats cannot be explained by an excessive loss of ascorbic acid from the kidney.

Ascorbic acid content of the tissues of vitamin A-deficient rats compared with that of non-deprived rats having a restricted food intake (paired feeding)

Male albino rats, $40-50 \mathrm{~g}$. in weight, were divided into two groups. Group I was given the diet deficient in vitamin $\mathbf{A}$, and became depleted, as evidenced by cessation of growth, after a period of 7 weeks, when the rats were killed. The diet of group 2 was supplemented with vitamin $A$ and, in addition, the food intake was restricted throughout the experiment to that of the rats in the first group. At the end of the 7 weeks' period some animals in this second group were given unrestricted food for a further period of I week before being killed (group 3).

The results are shown in Table I, Exp. 2. The hepatic reserves of vitamin $A$ of the animals in group I had been completely exhausted, whereas the rats in the other groups had adequate stores of the vitamin. No significant difference was found between the ascorbic acid content of the livers or suprarenal glands of the deprived animals (group I) and of the non-deprived ones with restricted food intake (group 2), but restriction of the diet did not eliminate the difference in the blood values for ascorbic acid of the two groups.

In the animals given vitamin $A$, and fed to appetite for I week after 7 weeks' restricted food intake, the concentration of ascorbic acid in the liver showed a mean level $50 \%$

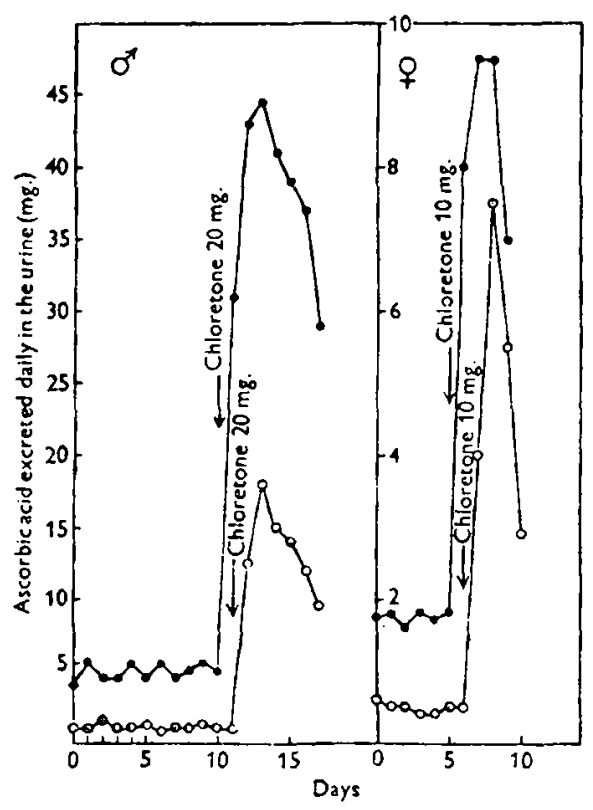

Fig. 2. Average amount of ascorbic acid excreted in the urine, before and after administration of 10 or $20 \mathrm{mg}$. chloretone daily for several days, by groups of six male or four female piebald rats. $\odot-\odot$ Rats deprived of vitamin $A$; - - rats not deprived of vitamin A. Both groups had an unrestricted food intake. higher than that of the animals in the other two groups. The blood value for ascorbic acid of these animals also was higher when compared with that of group 2 but, with the suprarenal glands, the week of unrestricted food intake had no such effect. 
An experiment similar to the last was carried out with piebald rats of both sexes (Table I, Exp. 3), and, with the male animals, essentially the same results were obtained as in Exps. I and 2, except that in the blood of the piebald male rats the difference between the concentration of ascorbic acid for the vitamin A-deficient animals and for the paired-fed ones receiving vitamin $A$ was much less than in that of rats of the albino strain, the difference between the means not being statistically significant ( $t$ found $=\mathrm{I} \cdot 54, t$ tabulated for $P$ O $\mathrm{I}=\mathrm{I} \cdot 8 \mathrm{I}$ ).

In female rats not deprived of vitamin $A$ restriction of food intake produced no decrease in the concentration of ascorbic acid in the tissues.

\section{The effect of chloretone on the synthesis of ascorbic acid in rats deprived and not deprived of vitamin $A$}

Longenecker, Fricke \& King (1940) showed that a variety of hypnotics stimulated the excretion of ascorbic acid in rats, paraldehyde and chloretone being the most effective. They confirmed by biological tests that the reducing substance present in the urine actually was ascorbic acid. Smythe \& King (1942) reported that an appreciable synthesis of ascorbic acid occurred in vitro in tissues from rats treated with chloretone. Similarly, both Bortree, Scheidenhelm \& Huffman (194I) and Moore \& Cotter (1945) showed that chloretone increased the excretion of ascorbic acid in cattle. There is, therefore, ample evidence that the administration of chloretone stimulates the synthesis of ascorbic acid.

If vitamin $\mathrm{A}$ is concerned specifically in this synthesis, the response of vitamin Adeficient animals to chloretone might be expected to be less than the response of normal animals. Moreover, as the degree of vitamin A deficiency develops, the response to the drug might be expected to become progressively, less. The effect of chloretone on the renal excretion of ascorbic acid and on the concentration of ascorbic acid in the body tissues of normal and vitamin A-deficient rats has, therefore, been studied. As in previous experiments the influence of food intake was taken into consideration.

\section{Urinary excretion of ascorbic acid}

Food intake unrestricted. Twelve male piebald rats were divided into two groups, the first group being given the vitamin A-deficient diet only, and the second group receiving a daily supplement of I $_{500}$ i.u. vitamin A. The animals in the two groups were litter-mates. When the animals in the deprived group had ceased growing, all the rats were placed in metabolism cages and $24 \mathrm{hr}$. samples of urine were collected for a period of 12-13 days. The urinary excretion of ascorbic acid remained reasonably constant for each rat during this period but, as noted previously, the level of excretion in the deprived group was, with the exception of one animal, lower than that in the nondeprived group.

At this stage each rat was dosed with $20 \mathrm{mg}$. of chloretone daily for a period of 7 days, and urine was collected as before. In all the animals the amount of ascorbic acid excreted rose sharply after the first dose of chloretone, and reached a peak after the second to third dose (Fig. 2), but the amount excreted by the deficient animals was 
lower than that by the non-deprived group. At the peak of excretion the non-deprived rats showed a mean daily rise of $40 \mathrm{mg}$./day compared with one of $15.5 \mathrm{mg}$./day shown by the deficient rats. The former appeared not to be adversely affected by the dose of chloretone given, whereas most of the deficient animals became comatose soon after dosing, and took some hours to recover.

A later experiment was carried out on female piebald rats. The procedure was identical with that already described, except that ro mg. chloretone were given instead of $20 \mathrm{mg}$. because the weight of these rats was about half that of the rats used in the previous experiment.

The pattern of the response to the drug was similar to that given by the male rats, although the difference between individual animals was greater. Once again the deficient animals excreted less ascorbic acid than the non-deficient ones. At the peak of excretion the seven nondeprived animals showed a mean rise of $9 \cdot 7$ $\mathrm{mg}$./day, compared with one of $6.1 \mathrm{mg}$./day shown by the four corresponding deprived animals which were not moribund at the end of the period of dosing. The average response of four deprived and four non-deprived comparable animals is shown in Fig. 2.

Food intake restricted (paired feeding). Twelve male piebald rats were divided into three groups, each' of which received the diet deficient in vitamin A. Each of the animals in group 2 received a weekly supplement of 1500 i.u. vitamin $A$, and their food intake was restricted from the beginning of the experiment to that of the animals in group I which received

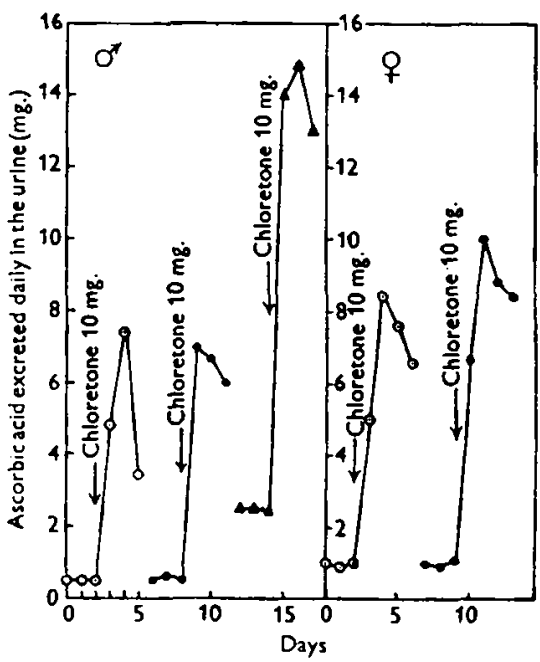

Fig. 3. Average amount of ascorbic acid excreted in the urine, before and after administration of $10 \mathrm{mg}$. chloretone daily for several days, by groups of four male or six female piebald rats. $\odot-\odot$ Group $\mathbf{r}$, rats deprived of vitamin $A$, food intake unrestricted; - - group 2, rats not deprived of vitamin $A$, food intake restricted to that of group I; $\triangle-\triangle$ group 3. rats not deprived of vitamin $A$, food intake unrestricted. no supplement. Group 3, which received the same vitamin A supplement as group 2, was not restricted in food intake. When the animals in group I showed evidence of vitamin A deficiency the rats from each group were dosed with ro mg. of chloretone daily. The amounts of ascorbic acid excreted in the urine are shown in Fig. 3.

The mean rise at the peak of excretion was (in $\mathrm{mg}$.):

Group I vitamin A-deficient

Group 2 vitamin A given, food intake restricted $6 \cdot 3$

Group 3 vitamin $A$ given, food intake unrestricted $12 \cdot 4$

The results show that the animals in group 2 did not excrete more ascorbic acid than the deficient animals, which suggests that the diminished response of the vitamin Adeficient male rat to chloretone can be entirely accounted for by its lowered food intake.

In a second experiment (Fig. 3 ) in which female piebald rats were used, the mean 
rise in urinary ascorbic acid at the peak of excretion was $8.9 \mathrm{mg} . /$ day in rats receiving vitamin $A$ with a restricted food intake, compared with a mean rise of $7.4 \mathrm{mg}$./day in the vitamin A-deficient animals. The results with the female animals were less clearcut than those with the males, which is probably due to the fact that the individual response to chloretone in the normal females was far more irregular than in the males. The difference between the two groups was, however, less marked than it was when the food of the animals given vitamin $A$ was unrestricted (see previous section), which again suggests that the food intake of the animals is more important than their state of vitamin $A$ deficiency in determining the amount of ascorbic acid excreted in response to chloretone.

\section{Ascorbic acid in tissues}

Food intake unrestricted. The ascorbic acid concentration in the tissues of vitamin Adeficient and non-deficient male piebald rats was determined after dosing with $20 \mathrm{mg}$. chloretone (Table 2, Exp. I). Some animals from the same batch, both deficient and non-deficient in vitamin $A$, were not dosed.

Administration of chloretone increased the ascorbic acid concentration in the liver and blood of the deprived animals, but produced no change in the ascorbic acid content of the suprarenal glands. With non-deprived animals chloretone produced some increase in the blood value for ascorbic acid, but had no effect on the ascorbic acid content of the liver or suprarenal glands.

A similar result was obtained with younger animals with a daily dose of $10 \mathrm{mg}$. of chloretone (Table 2, Exp. 2).

The increase of ascorbic acid in the tissues as a result of chloretone treatment was, therefore, as marked in the deficient as in the non-deficient animals, a finding which again suggests that there is no failure in the ability of the vitamin A-deficient rat to synthesize ascorbic acid.

Food intake restricted. A second experiment was carried out on thirteen pairs of male or female piebald rats, but this time the food intake of the non-deprived animals was restricted by paired feeding to that of the vitamin A-deficient rats. Ten pairs were given $10 \mathrm{mg}$. chloretone on 4 successive days, while the remaining three pairs were not dosed. All the animals were killed on the day after the last dose, and the ascorbic acid content of the liver, suprarenal glands and blood was determined.

The results are given in Table 3. The effect of chloretone on the animals in this experiment was found to be generally similar to that found with animals whose food intake was unrestricted.

Both in this experiment and in those described in the previous section, some of the vitamin A-deficient rats were moribund at the time of killing. It will be noted (Table 3 ) that in such animals the level of ascorbic acid in the liver was markedly reduced, even after chloretone.

\section{DISCUSSION}

Sure et al. (1939) reported that a depletion of vitamin A produced a fall in the concentration of ascorbic acid in the tissues of rats, but they subsequently found that an even greater reduction occurred as a result of riboflavin deficiency. Jonsson et al. (1942, 


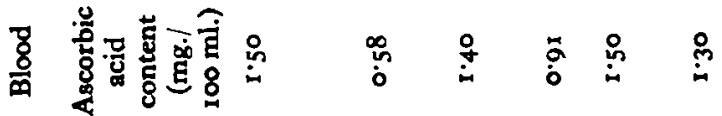

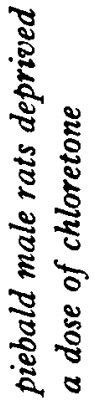

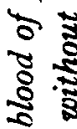

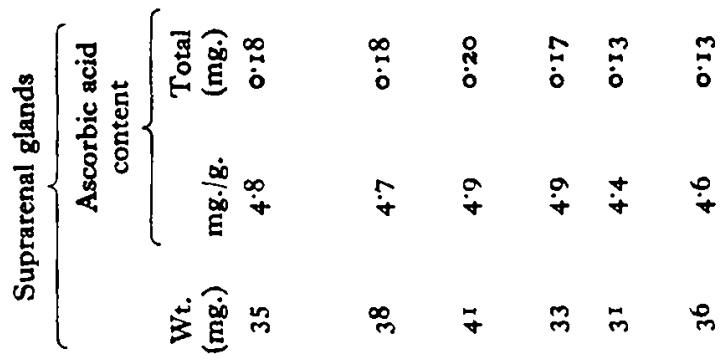

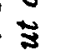

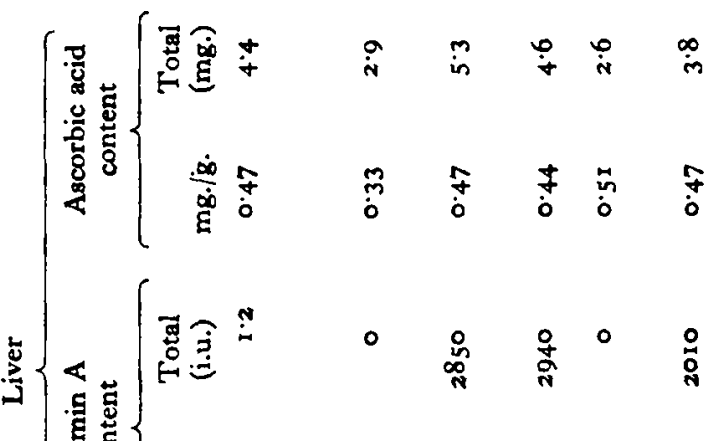

$\stackrel{-1}{\circ}$

胥

ป

ปั ชิ

క.

है है

क्षे

ลี

:

赵

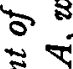

离 $\frac{2}{8}$

-

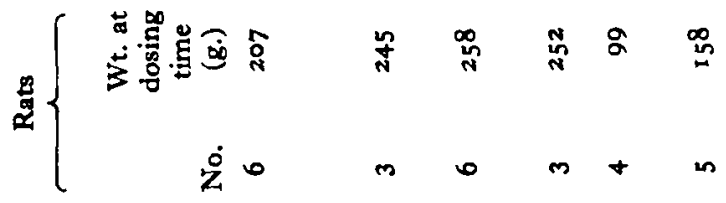

हु

$\frac{\pi^{2} \frac{8}{2}}{2}$

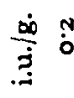

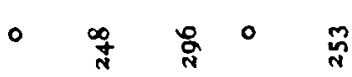

这芯

$\dot{\mathrm{N}}$

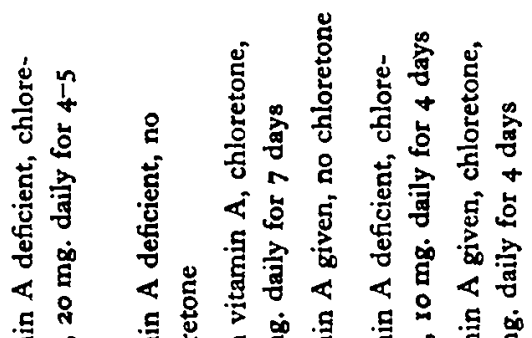

$\sum_{\substack{0 \\ 0}}^{\infty}$

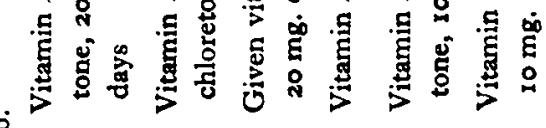

通 
Vol. 2

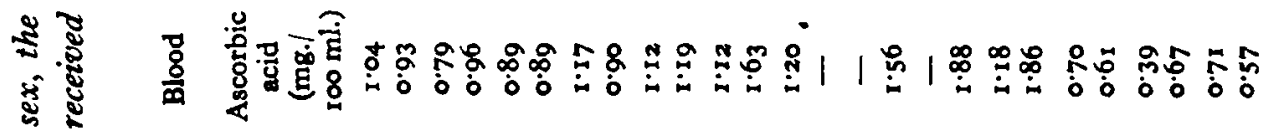

范

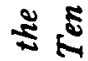

bi

艾

$\frac{3}{8}$

.ष है

¿

ㄴำ

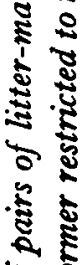

के

ะ

:

ङั

จ

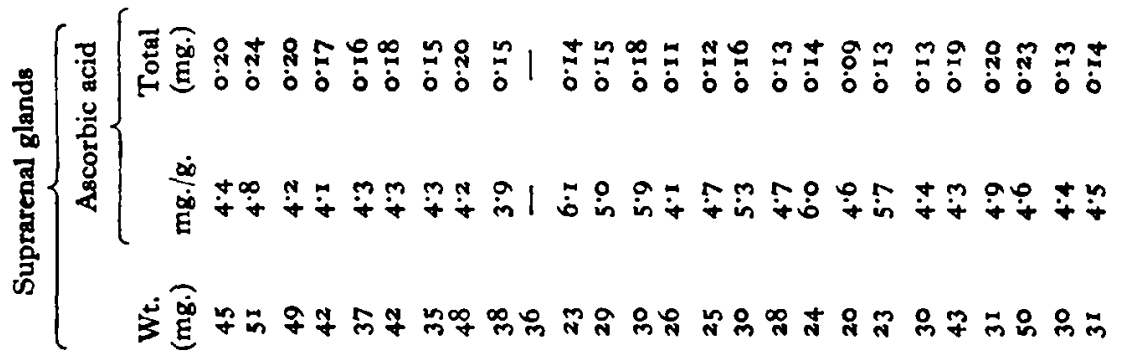

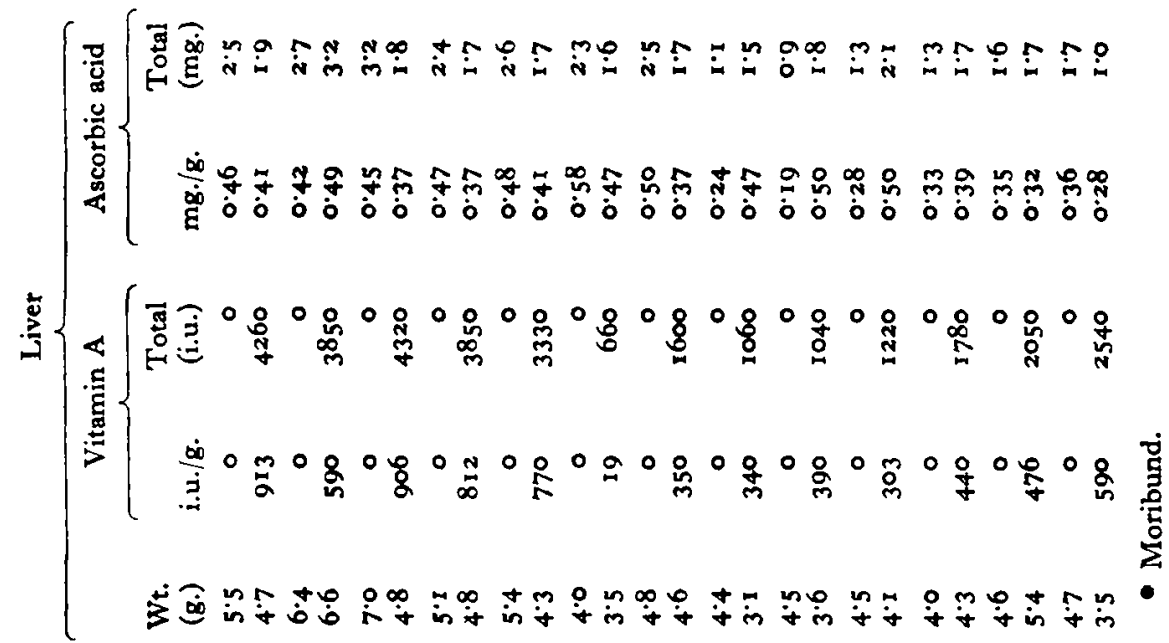

$0^{2}$

$\stackrel{2}{2}$

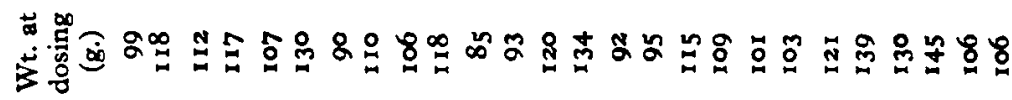

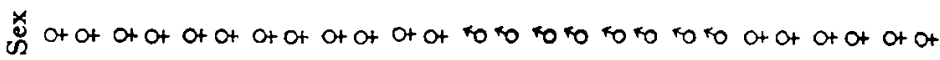

के है

$\div$

$\frac{\pi}{\pi} \frac{5}{0}$

3

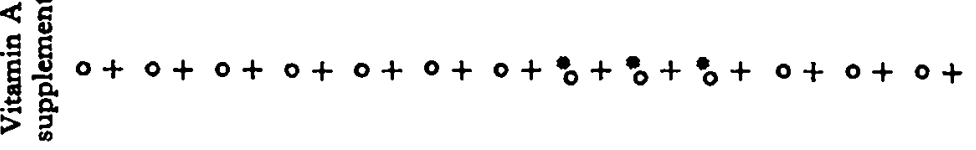

竎

.

.

त. 
1945) claimed to have produced scurvy-like alterations in the teeth of vitamin Adeficient rats, which they attributed to an impairment of ascorbic acid synthesis. These changes in the teeth were, however, unaffected by administration of ascorbic acid, but responded when vitamin $\mathrm{A}$ was given, showing that the lesions could not be attributed to a deficiency of ascorbic acid.

The results of the experiments described in this paper indicate that the lowered urinary excretion and tissue concentration of ascorbic acid found in vitamin Adeficient male rats can be attributed to the reduction of food intake which accompanies this condition. There was one observation which is difficult to explain, namely, that restriction of food intake did not reduce the blood values for ascorbic acid of nondeprived male albino rats to the level found in similar vitamin A-deficient animals (Table I, Exp. 2). In female rats, however, the concentration of ascorbic acid in the tissues was found to be unaffected by vitamin A deficiency or by restriction of food intake. Throughout these experiments the animals were assumed to be vitamin $\mathbf{A}$ deficient when growth had ceased and body-weight had begun to fall. This assumption was confirmed when, on analysis, the liver reserves of vitamin $A$ were found to be completely exhausted. In some cases vitamin A deficiency had progressed to such an extent that the animals were in a moribund condition when killed. These were the only animals in which a pronounced fall in the content of ascorbic acid in the liver was found, and this occurred in both males and females. Even in these cases, however, the amount of ascorbic acid in the suprarenal glands remained unchanged. It is doubtful if in such circumstances a fall of ascorbic acid in the liver is in any way significant.

The urinary excretion of ascorbic acid in response to chloretone appeared to be affected more by changes in food intake than by vitamin A deficiency. Administration of chloretone produced no change in the ascorbic acid concentration of the liver and suprarenal glands of the non-deprived male rat, which suggested that these tissues were already saturated with ascorbic acid. In the female, however, the drug raised the concentration of ascorbic acid in the liver; it is possible, therefore, that in the female the liver is not normally saturated with ascorbic acid.

The only occasion on which the urinary response to the drug was found to be noticeably reduced was when the rats appeared to be moribund at the time of killing. This occurred in five of the vitamin A-deficient animals, and, as previously stated, the concentration also of ascorbic acid in their livers was abnormally low.

Throughout all these experiments the level of ascorbic acid in the suprarenal glands was found to remain constant and to be unaffected by deprivation of vitamin $A$, restriction of food intake, or administration of chloretone.

\section{SUMMARY}

I. The concentration of ascorbic actd in the tissues of rats deprived and not deprived of vitamin A was determined under conditions in which the food consumption of the non-deprived animal was $(a)$ unrestricted and $(b)$ restricted to the level of the vitamin A-deficient group. The effect of chloretone on the synthesis of ascorbic acid in such deprived and non-deprived rats was likewise determined under similar conditions. 
2. The ascorbic acid content of the liver and blood was diminished in vitamin A-deficient male rats. This diminution was not due to increased urinary excretion of ascorbic acid but could, in the case of the liver, be accounted for by the lowered food intake of the deficient animals.

3. In the female animal vitamin A deficiency did not reduce the ascorbic acid concentration in the tissues. A reduction of the concentration of ascorbic acid in the liver occurred in those instances only where the deficiency had progressed to an extreme degree.

4. The rise in urinary excretion of ascorbic acid in response to chloretone was less in vitamin A-deficient rats than in non-deprived ones, but this difference was eliminated if the food intake of the latter was restricted to that of the deficient animals.

5. The oral administration of chloretone raised the concentration of ascorbic acid in the blood of vitamin A-deficient rats, both male and female (Table 2, Exp. I, and Table 3). It likewise increased the ascorbic acid level in the blood of non-deficient male and female rats with restricted food intake (males, Table 3 and Table r, Exp. 2, Group 2 and Exp. 3, Group 2; fermales, Table 3). Chloretone raised the concentration of ascorbic acid in the liver of vitamin A-deficient male and female animals (males, Table 2, Exp. I; females, Table 3). It increased the ascorbic acid concentration in the liver also of non-deficient female rats with restricted food intake (Table 3). Chloretone did not, however, increase the ascorbic acid content of the liver of non-deficient male animals with unrestricted food intake (Table 2). Chloretone did not significantly increase the ascorbic acid content of the suprarenal glands in any circumstances.

6. In these experiments no specific relationship was found between the rat's resources of vitamin $\mathbf{A}$ and its capacity to synthesize ascorbic acid.

We are indebted to Messrs B. J. Constable and A. Ward for their technical assistance. One of us (L.W.M.) took part in this work as a member of the Food Investigation staff of the Department of Scientific and Industrial Research working at the Dunn Nutritional Laboratory by arrangement with the Medical Research Council.

\section{REFERENCES}

Bortree, A. L., Scheidenhelm, E. C. \& Huffman, C. F. (194I). F. Dairy Sci. 24, 520.

Boyer, P. D., Phillips, P. H., Pounden, W. D., Jensen, C. W., Rupel, I. W. \& Nesbit, M. E. (1942). f. Nutrit. 23, 525 .

Boyle, P. E. (1933). F. dent. Res. 13, 39.

Davies, A. W. (1933). Biochem. F. 27, 1770.

Harris, L. J. \& Olliver, M. (1942). Biochem. F. 36, 155.

Hart, G. H., Goss, H. \& Guilbert, H. R. (1943). Amer. J. vet. Res. 4, 162.

Jonsson, G., Obel, A. L. \& Sjöberg, K. (1942). Z. Vitaminforsch. 12, 300.

Jonsson, G., Obel, A. L. \& Sjöberg, K. (1945). Z. Vitaminforsch. 15, 115.

Longenecker, H. E., Fricke, H. H. \& King, C. G. (1940). F. biol. Chem. 135, 497.

Mellanby, H. (1939). Brit. dent. F. 67, 187.

Mellanby, M. \& King, J. D. (1934). Brit. dent. F. 56, 538.

Moore, L. A. (1946). F. Nutrit. 31, 229.

Moore, L. A. \& Cotter, J. W. (1945). Y. Dairy Sci. 28, 495.

Orten, A. U., Burn, C. G. \& Smith, A. H. (1937). Proc. Soc. exp. Biol., N.Y., 36, 82.

Phillips, P. H., Lundquist, N. S. \& Boyer, P. D. (1941). F. Dairy Sci. 24, 977.

Roe, J. H. \& Kuether, C. A. (1943). J. biol. Chem. 147, 399. 
Rubin, M. \& Bird, H. R. (1943). Poult. Sci. 22, 53.

Smythe, C. V. \& King, C. G. (1942). F. biol. Chem. r42, 529.

Sure, B., Theis, R. M. \& Harrelson, R. T. (1939). F. biol. Chem. 129, 245.

Sutton, T. S., Kaeser, H. E. \& Hansard, S. L. (1942). F. biol. Chem. 144, 183.

Wolbach, S. B. \& Howe, P. R. (1933). Amer. F. Path. 9, 275.

Yudkin, S. (1941). Biochem. F. 35, 551 .

\title{
Comparison of Eye changes in Riboflavin Deficiency and in Tryptophan Deficiency in the Rat
}

\author{
By ANTOINETTE PIRIE, Nuffield Laboratory of Ophthalmology, Oxford
}

\section{(Received 19 September 1947)}

Deficiency of many different substances causes corneal vascularization in rats. It has been reported in vitamin A deficiency by Stephenson \& Clark (r920), in riboflavin deficiency by Bessey \& Wolbach (1939), in tryptophan deficiency and lysine deficiency by Totter \& Day (1942), in methionine and in protein deficiencies by Sydenstricker, Hall, Hock \& Pund (1946), in sodium deficiency by Follis, Day \& McCollum (194I), in zinc deficiency by Follis, Orent-Keiles \& McCollum (r942), in thallium poisoning by Donski (1932) and, on certain diets, in tyrosine and phenylalanine excess by Niven, Washburn \& Sperling (1946). The problem which has confronted everyone working in this field has been to account for this common sign arising from the lack in the food of so many entirely different substances or from the excess of others. Each deficiency may affect the corneal cells directly or indirectly through changes in the blood supply, and in the composition of the aqueous humour or lacrimal secretions. There may be many different stimuli for the ingrowth of corneal vessels, each deficiency providing one such stimulus, or, on the other hand, there may be a common factor among the changes caused by the lack of each separate substance and this may be the single stimulus for corneal vascularization. When an animal lacks a substance essential to life, many of its catabolic and synthetic systems are put out of gear so that in some cases induced deficiencies of other essential substances may occur. For example, Moore (1940) found that in rats lack of vitamin $E$ impaired the storage of vitamin $A$. Boyer, Phillips, Pounden, Jensen, Rupel \& Nesbit (1942) found that vitamin A-deficient rats had a lowered tissue vitamin C, and Pirie \& Wood (1946) found that vitamin Adeficient rabbits had lowered vitamin $C$ in their aqueous humour. Albanese, Holt, Kajdi \& Frankston (1943) found that tryptophan deficiency caused a reduction in haemoglobin and plasma protein, and Rosen, Huff \& Perlzweig (1946) found that nicotinic acid synthesis in the rat was depressed in tryptophan deficiency. Thus, each deficiency has repercussions on other, at first sight unrelated, chemical processes of the animal and may in this way lead to an unspecific common tissue reaction, e.g. corneal vascularization, although the primary function of the substance that is lacking is specific and unique. 